\title{
Babesias of red deer (Cervus elaphus) in Ireland
}

\author{
Annetta Zintl ${ }^{1}$, Eugene J Finnerty ${ }^{2}$, Thomas M Murphy ${ }^{3}$, Theo de Waal ${ }^{1}$, Jeremy S Gray ${ }^{2 *}$
}

\begin{abstract}
Blood samples were obtained from 38 wild red deer (Cervus elaphus) at two sites in Ireland and subjected to PCR analysis of the $18 \mathrm{~S}$ rRNA gene followed by sequencing. Two fragments of the $18 \mathrm{~S}$ rRNA gene were generated by two different PCR protocols and subsequent sequencing suggested that at least six of the deer were infected by a babesia that, in those loci, is indistinguishable from Babesia divergens, an important tick-borne pathogen of cattle and of zoonotic significance. Additionally, a B. odocoilei-like parasite was detected in three samples and a babesia that did not match any sequences in the GenBank database was found in five samples. Neither B. capreoli nor $B$. venatorum (EU1) were found. There have been several reports of $B$. divergens occurring in deer species, including red deer, roe deer (Capreolus capreolus) and reindeer (Rangifer tarandus). However, in view of recent re-sequencing of bovine-origin samples deposited previously in GenBank, it is unlikely that any of these sequences from deer are B. divergens. The present study describes the only deer piroplasm detected so far that shows complete identity with $B$. divergens, in just over half of the $18 \mathrm{~S}$ rRNA gene. The entire gene of this deer parasite should be analysed and transmission experiments undertaken before the infectivity of $B$. divergens for red deer can be confirmed.
\end{abstract}

\section{Introduction}

There has been considerable recent interest in the identity of Babesia spp. in deer, because of concerns about the health of endangered host species such as chamois (Rupicapra r. rupicapra) [1] and also because of the possibility of deer acting as reservoirs for important cattle parasites such as Babesia divergens [2]. Earlier studies on red (Cervus elaphus) and sika (C. nippon) deer babesias in Europe suggested that they were morphologically and antigenically indistinguishable from $B$. divergens, but were not transmissible to splenectomised calves. They were therefore tentatively identified as B. capreoli $[3,4]$, which was first observed in roe deer (Capreolus capreolus) [5]. With the advent of molecular taxonomy based on analysis of DNA sequences, several authors described parasites in roe, red or reindeer as $B$. divergens or $B$. divergens-like [2,6-12]. These authors based their conclusions on 18S rRNA gene sequence alignment, but none of their samples showed $100 \%$ similarity with $B$. divergens sequences of bovine origin in GenBank. Resequencing of the 18S rRNA gene from the same strains of $B$. divergens originally deposited in GenBank showed that all were in fact identical and that

\footnotetext{
* Correspondence: Jeremy.gray@ucd.ie

¿UCD School of Biology and Environmental Science, University College

Dublin, Ireland

Full list of author information is available at the end of the article
}

there were errors in the original sequences (Slemenda et al., unpublished, cited in [13]). This suggests that parasites showing less than $100 \%$ similarity for this gene should not be designated $B$. divergens and to date there are no studies showing that $B$. divergens occurs naturally in ruminant hosts other than cattle.

An opportunity to re-examine this situation arose during a serosurvey of deer parasites in free-ranging wild Irish deer. Blood samples from 38 red deer from two National Parks in different geographical locations were analysed by two PCR protocols targeting the $18 \mathrm{~S}$ rRNA gene, and the products then sequenced and aligned for identification purposes.

\section{Materials and methods}

Blood samples were collected from red deer shot by the National Parks and Wildlife Service as part of the seasonal cull in Glenveagh $(\mathrm{n}=27)$ and Killarney $(\mathrm{n}=11)$ (Figure 1). From each animal 3 to $4 \mathrm{~mL}$ whole blood were collected into EDTA. Following centrifugation and removal of plasma, the packed cell component was stored at $-20^{\circ} \mathrm{C}$. DNA was subsequently extracted from thawed and mixed $100 \mathrm{mg}$ packed cells of each sample using the High Pure PCR Template Preparation Kit (Roche, Burgess Hill, UK). A nested PCR protocol was used initially to screen all samples (protocol I). The positive samples were then additionally analysed using a
C Biomed Central

(c) 2011 Zintl et al; licensee BioMed Central Ltd. This is an Open Access article distributed under the terms of the Creative Commons Attribution License (http://creativecommons.org/licenses/by/2.0), which permits unrestricted use, distribution, and reproduction in any medium, provided the original work is properly cited. 


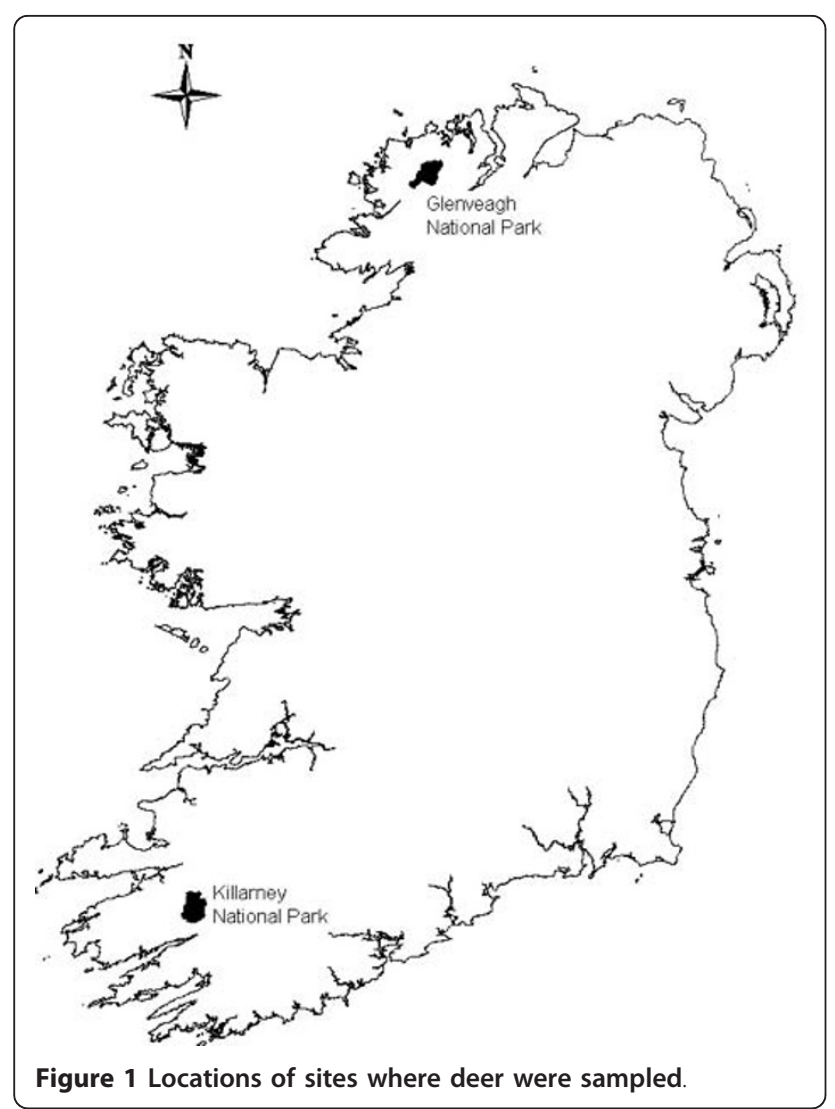

hemi-nested PCR protocol (protocol II). The two PCR protocols target different regions of the 18S rRNA gene and are modifications of previous published assays. Details are provided in Table 1 . B. divergens DNA extracted from a bovine isolate was used as a positive control. Negative controls were performed in the absence of template DNA. PCR products were fractionated on $2 \%$ agarose gels and visualised by staining with SYBR Safe DNA gel stain (Invitrogen, Paisley, UK). Amplicons were purified using the QIAquick PCR purification kit (Qiagen, Crawley, UK) and sequenced (GATC Biotech AG, Konstanz, Germany). Consensus sequences were obtained from between 5 to 14 forward and 2 reverse sequences, each. Comparisons were made with published sequences using NCBI Blast, aligned with the ClustalW2 sequence alignment programme and logged in GenBank under accession numbers GU475472 to GU475475. Because of insufficient sequence overlap at the 5 'end, logged sequences are approximately $40 \mathrm{bp}$ shorter than the amplicons.

Phylogenetic analysis of the relationship between sequences of our isolates and published sequence data was carried out using MEGA version 3.1 [14]. This software programme was used to construct a NeighbourJoining tree. Tree reliability was assessed by the bootstrap method with 1000 pseudoreplicates.

\section{Results}

The initial screen using PCR protocol I revealed that 18 deer carried Babesia spp. infections (26\%), with 17 originating from Glenveagh and 1 from Killarney (Table 2). The Babesia species present in these animals were identified by sequence-analysis of fragments amplified using both PCR protocols. Six samples from Glenveagh showed $100 \%$ similarity to B. divergens (GenBank AY046576) in both fragments of the 18S rRNA gene

Table 1 Details of the nested and hemi-nested PCR protocols used to screen deer blood samples for the presence of Babesia spp

\begin{tabular}{|c|c|c|c|c|}
\hline PCR protocol & Primers (positions)* & & Amplification protocol & Reference \\
\hline 1 & $1^{\text {st }}$ PCR: & & & \\
\hline Product size*: & BTH-1F (365-385) & $5^{\prime} \mathrm{cct}$ gag aaa cgg cta cca cat ct & $94^{\circ} \mathrm{C}: 10 \mathrm{~min}$, & {$[23]$} \\
\hline \multirow[t]{4}{*}{$561 \mathrm{bp}$} & BTH-1R (1031-1050) & $5^{\prime}$ ttg cga cca tac tcc ccc ca & $\begin{aligned} 40 \text { cycles: } 95^{\circ} \mathrm{C}: & 30 \mathrm{~s}, 68^{\circ} \mathrm{C}: 1 \mathrm{~min}, 72^{\circ} \mathrm{C}: 1 \mathrm{~min} \\
& 72^{\circ} \mathrm{C}: 10 \mathrm{~min}\end{aligned}$ & \\
\hline & nested PCR: & & & \\
\hline & GF2 (466-487) & $5^{\prime}$ gtc ttg taa ttg gaa tga tgg & $94^{\circ} \mathrm{C}: 10 \mathrm{~min}$ & [19] \\
\hline & GR2 (1006-1026) & $5^{\prime}$ cca aag act ttg att tct ctc & $\begin{aligned} 40 \text { cycles: } 95^{\circ} \mathrm{C}: & 30 \mathrm{~s}, 60^{\circ} \mathrm{C}: 1 \mathrm{~min}, 72^{\circ} \mathrm{C}: 1 \mathrm{~min} \\
& 72^{\circ} \mathrm{C}: 10 \mathrm{~min}\end{aligned}$ & \\
\hline$\|$ & $1^{\text {st }}$ PCR: & & & \\
\hline Product size*: & Babfor (959-977) & 5'gac tag gga ttg gag gtc & $94^{\circ} \mathrm{C}: 10 \mathrm{~min}$ & {$[24]$} \\
\hline \multirow[t]{4}{*}{$576 \mathrm{bp}$} & Babrev (1589-1610) & 5'gaa taa ttc acc gga tca ctc & $\begin{array}{c}35 \text { cycles: } 95^{\circ} \mathrm{C}: 1 \min , 53^{\circ} \mathrm{C}: 1.5 \min , 72^{\circ} \mathrm{C}: 1.5 \min \\
72^{\circ} \mathrm{C}: 10 \min \end{array}$ & \\
\hline & nested PCR & & & \\
\hline & BT2-F (1035-1055) & 5'gga gta tgg tcg caa gtc tg & $94^{\circ} \mathrm{C}: 10 \mathrm{~min}$ & [23] \\
\hline & Babrev & & $\begin{array}{c}35 \text { cycles: } 95^{\circ} \mathrm{C}: 1 \min , 53^{\circ} \mathrm{C}: 1.5 \mathrm{~min}, 72^{\circ} \mathrm{C}: 1.5 \mathrm{~min} \\
72^{\circ} \mathrm{C}: 10 \mathrm{~min}\end{array}$ & \\
\hline
\end{tabular}

\footnotetext{
* product sizes and primer positions according to reference sequence AY046576.
} 
Table 2 Presence of Babesia spp. in red deer whole blood samples from Glenveagh and Killarney

\begin{tabular}{|c|c|c|c|}
\hline Glenveagh & & & \\
\hline Deer $N^{\circ}$ & $+/-$ & species ID according to product I & species ID according to product II \\
\hline G1 & + & 98\% identical with B. odocoilei* & 96\% identical with B. odocoilei, B. divergens, EU1** \\
\hline G2 & + & $100 \%$ identical to B. divergens*** & $100 \%$ identical to B. divergens*** \\
\hline G3 & + & 98\% identical with B. odocoilei* & 96\% identical with B. odocoilei, B. divergens, EU1** \\
\hline G4 & - & & \\
\hline G5 & + & $100 \%$ identical to B. divergens ${ }^{* * *}$ & Babesia sp**** \\
\hline G6 & + & $100 \%$ identical to $B$. divergens s** $^{* *}$ & $100 \%$ identical to $B$. divergens*** \\
\hline G7 & + & Babesia sp s**** $^{* *}$ & 96\% identical with B. odocoilei, B. divergens, EU1** \\
\hline G8 & - & & \\
\hline G9 & - & & \\
\hline G10 & + & Babesia sp s.*** $^{* *}$ & 96\% identical with B. odocoilei, B. divergens, EU1** \\
\hline G11 & - & & \\
\hline G12 & - & & \\
\hline G13 & + & $100 \%$ identical to B. divergens*** & $100 \%$ identical to B. divergens ${ }^{* * *}$ \\
\hline G14 & + & $100 \%$ identical to B. divergens ${ }^{* * *}$ & $100 \%$ identical to $B$. divergens*** \\
\hline G15 & + & Babesia sp**** & $100 \%$ identical to B. divergens*** \\
\hline G16 & + & Babesia sp s*** $^{* *}$ & - \\
\hline G17 & - & & \\
\hline G18 & + & $100 \%$ identical to B. divergens*** & $100 \%$ identical to B. divergens*** \\
\hline G19 & + & $100 \%$ identical to B. divergens ${ }^{* * *}$ & - \\
\hline G20 & - & & \\
\hline G21 & - & & \\
\hline $\mathrm{G} 22$ & + & Babesia sp**** & Babesia $s p^{* * * *}$ \\
\hline G23 & + & $100 \%$ identical to B. divergens s** $^{* *}$ & $100 \%$ identical to B. divergens*** \\
\hline G24 & - & & \\
\hline G25 & + & $100 \%$ identical to B. divergens*** & Babesia sp $p^{* * * *}$ \\
\hline G26 & - & & \\
\hline G27 & + & 98\% identical with B. odocoilei* & Babesia sp $p^{* * * *}$ \\
\hline Killarney & & & \\
\hline Deer $N^{\circ}$ & $+/-$ & species ID according to product I & species ID according to product II \\
\hline KR1 & - & & \\
\hline KR2 & - & & \\
\hline KR3 & - & & \\
\hline KR4 & - & & \\
\hline KR5 & + & $100 \%$ identical to B. divergens ${ }^{* * *}$ & 96\% identical with B. odocoilei, B. divergens, EU1** \\
\hline KR6 & - & & \\
\hline KR7 & - & & \\
\hline KR8 & - & & \\
\hline KR9 & - & & \\
\hline KR10 & - & & \\
\hline KR11 & - & & \\
\hline
\end{tabular}

Babesia spp were identified by sequence allignment of amplification products from PCR protocols I and II (products I and II respectively).

* sequence identical between G1, G3 and G27 (reference sequence: AY046577).

** sequence identical between G1, G3, G7, G10, KR5 (reference sequences: AY046575, AY046576, AY046577).

*** reference sequence: AY046576.

**** amplicons only identifiable to genus level due to poor sequencing data. 
(logged in GenBank under accession numbers GU475472 (PCR protocol I) and GU475473 (protocol II)). In a further five isolates one amplicon (resulting either from PCR protocol I or II) showed $100 \%$ B. divergens similarity, although the second amplicon could only be identified to genus level. In addition, identical nested PCR products (amplified using protocol I) from three Glenveagh deer samples were $98 \%$ similar to B. odocoilei (GenBank AY046577) and have been logged as GU475474. Five products from PCR protocol II (4 from Glenveagh and 1 from Killarney) were also identical to each other but did not closely match any Babesia species in the GenBank database (96\% similarity with $B$. divergens, B. odocoilei and EU1) (accession number GU475475) (Table 2). Figure 2 shows the phylogenetic positions of the amplicons arising from PCR protocol I, which proved to be more discriminating than PCR protocol II. The latter protocol generated amplicons that did not differentiate bovine-origin $B$. divergens from any of the $B$. divergens-like species, but showed that the unknown Babesia sp. is clearly separate from $B$. divergens, B. odocoilei and B. venatorum (Figure 3). The remaining positive PCR amplicons could only be identified to Babesia genus level due to poor sequencing data.



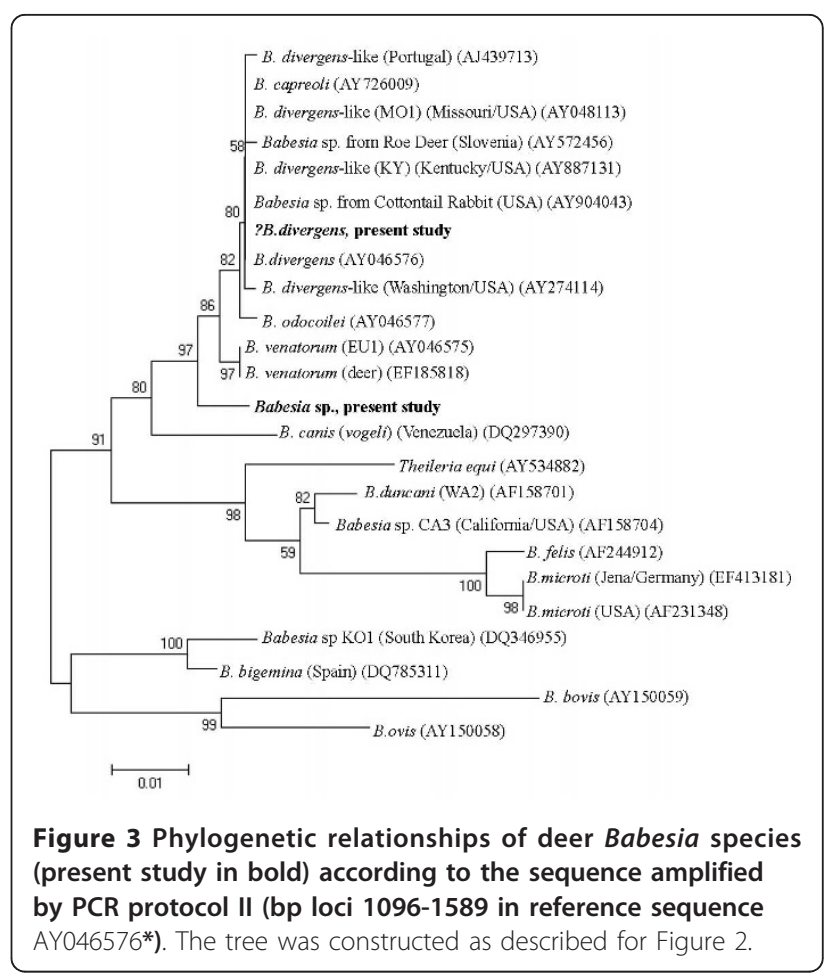

\section{Discussion}

Reports of the identification of $B$. divergens in reindeer [8], roe deer $[2,6,9,12]$, red deer [2] and chamois [1] were noteworthy because this parasite is not only an important pathogen of cattle but is also zoonotic, causing a dangerous fulminating disease in splenectomised patients $[15,16]$. The presence of $B$. divergens in freeranging wild deer would affect our understanding of both bovine and human babesiosis epidemiology. However, reliance on similarity of fragments of the $18 \mathrm{~S}$ rRNA gene for identification of this parasite is questionable. Although this gene is of great taxonomic value within the Apicomplexa, it has been suggested that it may not discriminate well between very closely related parasites [11]. Furthermore, few of the recent studies on babesia in European deer analysed the whole gene, or attempted infection with deer parasites of splenectomised cattle or gerbils (Meriones unguiculatus), both of which infections are reliable markers for $B$. divergens identity [16]. The most complete sequences analysed were from babesias in farmed reindeer in Scotland [8] and from roe deer in Slovenia [2]. In both these studies it was concluded that the high level of similarity $(99.8$ and $99.6 \%$ respectively) when compared with $B$. divergens GenBank depositions made in the mid-90s (U16370, UO7885 and Z48751) justified identity with $B$. divergens. However, when the whole $18 \mathrm{~S}$ rRNA gene from the original $B$. divergens strains were resequenced, along with several others, it was found that all were 
identical and the only strain that had been accurately sequenced among the early GenBank depositions was U16370 (Slemenda et al., unpublished, cited in [13]). This calls into question $B$. divergens identity of any isolates showing less than $100 \%$ similarity to U16370. Although further bovine $B$. divergens sequence data were recently deposited in GenBank, these show only one (EF458223, EF458224, EF458227) or two (EF458219) base pair differences from the approximately 12 accurate sequences of other $B$. divergens bovine isolates in the data base. None of the deer-derived babesia isolates referred to above showed less than four basepair differences and in only one study [8] was an attempt made to infect gerbils. No infection occurred but this could have been due to reduced viability of the parasites resulting from the delay in their arrival at the laboratory by mail.

The tentative identification of $B$. divergens in the present study is based on analysis of two fragments of the 18S rRNA gene (bp loci 527-1005 and 1096-1589 in the bovine origin reference sequence, AY046576), more than half the total gene of $1728 \mathrm{bp}$. In the other publications that reported detection of $B$. divergens and where a significantly large proportion of the gene was analysed, base pair differences compared with AY046576 occurred at the following base pair loci - 632, 663, 1277 (AY098643 [8]); 373, 631, 663, 804, 1365, 1423 (AY572456 [2]), whereas no differences from our sequences were found at these loci. Schmid et al. [11] detected $B$. divergens-like piroplasms with a similar level of $18 \mathrm{~S}$ rDNA similarity (99.5\% and $99.6 \%$ ) in roe deer and chamois. They did not identify these parasites as $B$. divergens and suggested they should be regarded as B. capreoli, although the sequences (EU182596 and EU182597) do not show 100\% 18S rDNA similarity with this species either (AY726009). It is possible that bovine $B$. divergens, which evidently shows negligible variability in the $18 \mathrm{~S}$ rRNA gene $[13,17]$, is a variant of deer origin that has developed specificity for cattle.

In striking contrast to the above three studies, the $B$. divergens-like sequences from the present study showed no differences from bovine $B$. divergens sequences at base pair loci 527-1005 and 1096-1589. Whether or not this parasite is truly identical with bovine $B$. divergens requires further study, but this is also the first reliable demonstration of a $B$. divergens-like piroplasm (even if not $B$. divergens) in red deer because the only previous study that considered this deer species [2], apparently did not attempt to sequence the PCR product.

The highest proportion of babesia-infected deer occurred in the Glenveagh herd and most identifiable babesia sequences were also obtained from this herd. Although serology detected antibodies in the majority of the Killarney samples (unpublished data), no identifiable amplicons could be generated by PCR. It is not obvious why these differences occurred. The deer in all the locations were exposed to heavy tick (Ixodes ricinus) challenge judging by the numerous attached ticks observed at culling.

It is of interest that neither B. capreoli nor B. venatorum were found in the present study. B. capreoli was first described by Enigk and Friedhoff [5], in roe deer based primarily on morphology. Adam and Blewett [3], and Gray et al. [4], tentatively identified parasites isolated from red deer and sika deer respectively as B. capreoli, based on origin, morphology and antigenicity. In both cases transfer to splenectomised calves failed to result in infection, suggesting that these parasites were not $B$. divergens, though in the light of recent DNA analysis data it seems likely that they were $B$. divergens-like parasites. More recently, DNA analysis by Hoby et al. [7] and Malandrin et al. [18] confirmed that $B$. capreoli occurs in roe deer and the former authors also detected this parasite in chamois and red deer, though single samples only were positive in these latter host species. B. venatorum (EU1) first came to scientific notice as a zoonotic infection [13], and has since then been firmly associated with roe deer $[18,19]$, but has not so far been detected in red deer. The apparent absence of both B. capreoli and B. venatorum in the present study correlates well with the fact that roe deer do not occur in Ireland [20].

B. odocoilei is a piroplasm of American white-tailed deer (Odocoileus virginianus) and close relatives of this parasite have been detected in European ticks (I. ricinus) by PCR $[13,21]$. Unfortunately no sequence data are available from the PCR products of the tick analyses for comparison with the present study, which appears to be the first record of such a piroplasm in European deer, though the $B$. odocoilei-like parasite detected by Hilpertshauser et al. [22] was in ticks removed from roe deer and which therefore contained deer blood. One further sequence in the present study was identifiable as Babesia sp. but did not match any sequence in GenBank. Since it was identical in samples from five individual deer, it may represent a new babesia $18 \mathrm{~S}$ rDNA sequence.

Analysis of the complete 18S rRNA gene would, of course, have provided a greater level of confidence in the identity of the babesias detected in this study. Unfortunately, available resources did not permit this. Nevertheless, the gene fragment analysis presented here suggests that there are at least two Babesia species, if not three, in the red deer sampled in this study. The significance of these parasites as disease agents is unknown and further studies, in addition to gene analysis, including isolation of the parasites and transmission studies in in vitro or in vivo systems are necessary to establish 
their identities, particularly that of the putative $B$. divergens.

\section{Acknowledgements}

We are grateful to the rangers of the National Parks and Wildlife Service at Glenveagh and Killarney for facilitating collection of samples.

\section{Author details}

${ }^{1}$ UCD School of Agriculture, Food Science and Veterinary Medicine, University College Dublin, Ireland. ${ }^{2}$ UCD School of Biology and Environmental Science, University College Dublin, Ireland. ${ }^{3}$ Central Veterinary Laboratories, Backweston, Co. Kildare, Ireland.

\section{Authors' contributions}

AZ performed the DNA analysis and was joint lead author of the manuscript, EF and TM collected the samples and participated in writing the manuscript, TDW provided advice on DNA analysis and participated in writing the manuscript, JG planned and co-ordinated the study and was joint lead author of the manuscript. All authors read and approved the final manuscript.

\section{Competing interests}

The authors declare that they have no competing interests.

Received: 8 February 2010 Accepted: 7 October 2010

Published: 18 January 2011

\section{References}

1. Hoby S, Robert N, Mathis A, Schmid N, Meli ML, Hofmann-Lehmann R Lutz H, Deplazes P, Ryser-Degiorgis MP: Babesiosis in free-ranging chamois (Rupicapra r. rupicapra) from Switzerland. Vet Parasitol 2007, 148:341-345.

2. Duh D, Petrovec M, Bidovec A, Avsic-Zupanc T: Cervids as Babesiae hosts, Slovenia. Emerg Infect Dis 2005, 11:1121-1123.

3. Adam KM, Blewett DA, Brocklesby DW, Sharman GA: The isolation and characterization of a Babesia from red deer (Cervus elaphus). Parasitology 1976, 73:1-11.

4. Gray JS, Murphy TM, Taylor SM, Blewett DA, Harrington R: Comparative morphological and cross transmission studies with bovine and deer babesias in Ireland. Prev Vet Med 1990, 9:185-193.

5. Enigk K, Friedhoff K: Babesia capreoli n. sp. in the deer (Capreolus capreolus L.). Z Tropenmed Parasitol 1962, 13:8-20, In German.

6. Cancrini G, Gabrielli S, Lori A, Grifoni G, Calderini P: Morphology and genetics of a Babesia isolate from Capreolus capreolus. J Wildl Dis 2008, 44:168-171.

7. Hoby S, Mathis A, Doherr MG, Robert N, Ryser-Degiorgis MP: Babesia capreoli infections in alpine chamois (Rupicapra r. rupicapra), roe deer (Capreolus c. capreolus) and red deer (Cervus elaphus) from Switzerland. J Wildl Dis 2009, 45:748-753.

8. Langton C, Gray JS, Waters PF, Holman PJ: Naturally-acquired babesiosis in a reindeer (Rangifer tarandus tarandus) herd in Great Britain. Parasitol Res 2003, 89:194-198.

9. Sawczuk M, Maciejewska A, Adamska M, Skotarczak B: Roe deer (Capreolus capreolus) and red deer (Cervus elaphus) as a reservoir of protozoans from Babesia and Theileria genus in north-western Poland. Wiad Parazyto 2005, 51:243-247, In Polish.

10. García-Sanmartín J, Nagore D, García-Pérez AL, Juste RA, Hurtado A: Molecular diagnosis of Theileria and Babesia species infecting cattle in Northern Spain using reverse line blot macroarrays. BMC Vet Res 2006, 2:16.

11. Schmid N, Deplazesm P, Hobym S, Ryser-Degiorgis MP, Edelhofer R, Mathis A: Babesia divergens-like organisms from free-ranging chamois (Rupicapra r. rupicapra) and roe deer (Capreolus c. capreolus) are distinct from $B$. divergens of cattle origin - an epidemiological and molecular genetic investigation. Vet Parasitol 2008, 154:14-20.

12. Tampieri MP, Galuppi R, Bonoli C, Cancrini G, Moretti A, Pietrobelli M: Wild ungulates as Babesia hosts in northern and central Italy. Vector Borne Zoonotic Dis 2008, 8:667-674.
13. Herwaldt BL, Caccio S, Gherlinzoni F, Aspöck H, Slemenda SB, Piccaluga P, Martinelli G, Edelhofer R, Hollenstein U, Poletti G, Pampiglione S, Löschenberger K, Tura S, Pieniazek NJ: Molecular characterization of a non-Babesia divergens organism causing zoonotic babesiosis in Europe. Emerg Infect Dis 2003, 9:942-948.

14. Kumar S, Tamura K, Nei M: MEGA3: Integrated software for molecular evolutionary genetics analysis and sequence alignment. Brief Bioinform 2004, 5:150-163.

15. Hunfeld KP, Hildebrandt A, Gray JS: Babesiosis: Recent insights into an ancient disease. Int J Parasitol 2008, 38:1219-1237.

16. Zintl A, Mulcahy G, Skerrett HE, Taylor SM, Gray JS: Babesia divergens, a bovine blood parasite of veterinary and zoonotic importance. Clin Rev Microbiol 2003, 16:622-636.

17. Gray J, Zintl A, Hildebrandt A, Hunfeld KP, Weiss L: Zoonotic babesiosis: Overview of the disease and novel aspects of pathogen identity. Ticks Tick-borne Dis 2010, 1:3-10

18. Malandrin L, Jouglin M, Sun Y, Brisseau N, Chauvin A: Redescription of Babesia capreoli (Enigk and Friedhoff, 1962) from roe deer (Capreolus capreolus): Isolation, cultivation, host specificity, molecular characterisation and differentiation from Babesia divergens. Int I Parasitol 2010, 40:277-284.

19. Bonnet S, Jouglin M, L'Hostis M, Chauvin A: Babesia sp. EU1 from roe deer and transmission within Ixodes ricinus. Emerg Infect Dis 2007, 13:1208-1210.

20. Whitehead GK: The deer of Great Britain and Ireland. Routledge and Kegan Paul, London; 1964.

21. Duh D, Petrovec M, Avsic-Zupanc T: Diversity of Babesia infecting European sheep ticks (Ixodes ricinus). J Clin Microbiol 2001, 39:3395-3397.

22. Hilpertshauser H, Deplazes P, Schnyder M, Gern L, Mathis A: Babesia spp. identified by PCR in ticks collected from domestic and wild ruminants in southern Switzerland. Appl Environ Microbiol 2006, 72:6503-65077.

23. Criado-Fornelio A, Martinez-Marcos A, Buling-Saraña A, Barba-Carretero JC Molecular studies on Babesia, Theileria and Hepatozoon in southern Europe. Part II. Phylogenetic analysis and evolutionary history. Vet Parasitol 2003, 114:173-194

24. Blaschitz M, Narodoslavsky-Gföller M, Kanzler M, Stanek G, Walochnik J: Babesia species occurring in Austrian Ixodes ricinus ticks. Appl Environ Microbiol 2008, 74:4841-48.

doi:10.1186/1297-9716-42-7

Cite this article as: Zintl et al: Babesias of red deer (Cervus elaphus) in Ireland. Veterinary Research 2011 42:7.

\section{Submit your next manuscript to BioMed Central and take full advantage of:}

- Convenient online submission

- Thorough peer review

- No space constraints or color figure charges

- Immediate publication on acceptance

- Inclusion in PubMed, CAS, Scopus and Google Scholar

- Research which is freely available for redistribution
C Biomed Central 